\title{
A formação do campo artístico na capital federal do Brasil*
}

\author{
JoÃo Gabriel Lima CruZ TeiXeira**
}

\begin{abstract}
Resumo: $\mathrm{O}$ artigo apresenta excertos de um livro em processo de finalização sobre o mundo das artes em Brasília, a capital modernista planejada como uma utopia socialista, baseados em entrevistas realizadas com 23 excelências desse campo de produção cultural. Mostra o caráter de fronteira dessa sociedade e o pioneirismo desses artistas, os aspectos místico-esotéricos e as influências ecológicas no processo de educação sentimental deles. Apresenta ainda crítica remissiva sobre o imaginário criado sobre a cidade e a tentativa de construção da identidade de um sítio cultural extremamente novo, com base em casos de artistas que lograram projeção nacional e mesmo internacional.
\end{abstract}

Palavras-chave: Brasília; campo artístico; modernismo; educação sentimental.

"Certa vez, numa tarde de céu carregado de nuvens, a luz do sol filtrou-se, caindo exatamente sobre a cúpula, como um jacto de poderoso holofote. Houve diferentes interpretações de fenômeno natural. Fizeram-se fotografias. Mas muita gente crédula, ligando o destino de Brasília ao misticismo religioso, chegou a interpretar o facho luminoso como um sinal celeste, assinalando o futuro da Capital em construção [...] E assim, para os olhos de quem quer ver e para a alma de quem ama a cidade nova, os espetáculos da arquitetura de Niemeyer, aliada ao urbanismo de Lúcio Costa, são estranhos e vários [...] Muitas vezes a gente tem a impressão de que saiu de uma rua e entrou num imenso salão de pinturas surrealistas ou num corredor de caleidoscópios coloridos [...]". (Luz, 1982, p. 167 e 168)

\section{Introdução}

Este trabalho resulta de um projeto de pesquisa cujo objetivo inicial era identificar as razões para uma presumida fertilidade diferencial para a produção e a maturação de talentos em um

\footnotetext{
* Trabalho apresentado no XXV Congresso da Alas, GT As Cidades Latino-americanas no Novo Milênio, realizado em Porto Alegre entre 22 e 26 de agosto de 2005.

** Professor titular da UnB.
}

número significativo de áreas artísticas em Brasília, quando comparada com outros centros urbanos brasileiros maiores. Ele também objetivava investigar a especificidade daquela cidade que responderia por tal diferencial, se existente.

O fato é que, tomando a imprensa local como referência, a apresentação de nomes originários de Brasília como highlights é recorrente em um número de diferentes áreas artísticas. Origem aqui significa o ambiente social do período de formação, isto é, da descoberta e do desenvolvimento daquele talento.

A questão principal era então descobrir se essa impressão poderia encontrar apoio em dados objetivos. Contudo, foi descoberto logo no começo da pesquisa que esses dados não estão disponíveis na atualidade. Conseqüentemente, decidiu-se que um procedimento promissor seria a análise dos discursos dos protagonistas do mercado cultural local - as excelências, ${ }^{1}$ neste caso - em relação aos seus proces-

\footnotetext{
1. O termo está sendo usado aqui para ressaltar esse protagonismo e designar aqueles que se distinguiram em suas respectivas atividades artísticas, logrando reconhecimento nacional ou, mesmo, internacional.
} 
sos de formação e os passos que seguiram antes de sua projeção nacional.

Uma lista preliminar de áreas foi selecionada, e nomes de reconhecida expressão foram identificados. Uma lista de questões relacionada aos interesses expostos foi organizada, para ser apresentada a 23 deles. ${ }^{2}$ Esperava-se que esse procedimento detectasse frestas nos seus discursos, as quais permitiriam a percepção de informações que teriam sido recusadas previamente por eles em uma primeira aproximação.

Procedeu-se à análise dessas entrevistas, o que conduziu o pesquisador a ensaiar um livro sobre a configuração do mundo artístico de Brasília e de sua contribuição para a formação da identidade local, ou seja, a identidade social de uma cidade de 45 anos de idade, fruto de um projeto urbanístico modernista que representou a construção de um ideal utópico socialista. Este artigo fará parte do livro ora em fase de conclusão.

Ao adotarem-se variáveis educacionais, urbanísticas, místicas e ambientais, garimpadas e recuperadas da literatura já produzida sobre Brasília, pretendeu-se definir os elementos de um processo de educação sentimental, inspirado livremente pelo conceito de Bourdieu (1996, p. $24),{ }^{3}$ ou melhor, quase o parafraseando. Entende-se que esse procedimento permitiria uma incursão exploratória da gênese dos principais

\footnotetext{
2. Os nomes foram selecionados a partir de discussões realizadas com os membros da equipe da pesquisa e informantes privilegiados sobre a produção artística local. Entre eles constam, além dos expoentes fundadores (Oscar Niemeyer, Lucio Costa, Athos Bulcão, Wladimir Murtinho, Dulcina de Morais); artistas pioneiros (Luiz Humberto Pereira, fotógrafo, e Wladimir Carvalho, cineasta); artistas visuais (Cildo Meireles, Luiz Áquila, Glenio Bianchetti, Evandro Salles e Marilia Panitz); artistas cênicos (Hugo Rodas, Françoise Forton, Adriano e Fernando Guimarães, Marcelo Saback); músicos (Fê Lemos, baterista da banda Capital Inicial; Gutze Woortmann, da Plebe Rude; Dado Villa Lobos, da Legião Urbana; Loro Jones, do Capital Inicial); promotores cultrais (Maria Duarte); cantor (Ney Matogrosso).

3. Discorrendo sobre o campo artístico, Bourdieu afirma "Campo de forças possíveis, que se exercem sobre todos os corpos que nele podem entrar, o campo do poder é também um campo de lutas, e talvez, a esse título, comparado a um jogo: as disposições, ou seja, o conjunto das propriedades incorporadas, inclusive a elegância, a naturalidade ou mesmo a beleza, e o capital sob suas diversas formas, econômica, cultural social, constituem trunfos que vão comandar a maneira de jogar e o sucesso no jogo, em suma, todo o processo de envelhecimento social que Flaubert chama de "educação sentimental'".
}

habitus $^{4}$ presentes na formação do campo artístico em Brasília, considerando o caráter pioneiro dos atores envolvidos nesse processo e que eles atuam em um locus que pode também ser considerado como de fronteira, ou seja, onde esses elementos ainda não estão cristalizados e, portanto, não são de fácil percepção.

Pretendeu-se fornecer mais que uma visão panorâmica de como as "excelências" responderam às questões propostas pelo projeto. Primeiro de tudo, é digno de menção o fato de que elas constituem um grupo bastante heterogêneo de artistas, em diferentes gêneros e faixas etárias. Esperava-se que essa busca na subjetividade das excelências oferecesse uma configuração das disposições artísticas em voga, ou melhor, da constituição de seus habitus. Em suma, na feitura do livro, privilegiou-se a busca pelos trunfos e disposições referidos por Bourdieu.

\section{A literatura}

Entre as obras sociológicas mais recentes sobre Brasília, destaca-se a organizada por Nunes (1997), que é composta de artigos produzidos por um grupo de estudiosos do Departamento de Sociologia da Universidade de Brasília. Entre esses estudos, destacaram-se trabalhos que lidam com os temas do misticismo, do patrimônio arquitetônico, da discriminação socioespacial e de tribos pós-modernas. É digo de nota que três deles inspiraram alguns dos insights que orientaram a execução do projeto. Contudo, nenhum dos três artigos está diretamente relacionado aos tópicos incluídos inicialmente no projeto de pesquisa original. Eles foram considerados como constitutivos do processo de educação sentimental almejado porque fazem parte do imaginário sobre Brasília e se prestam insofismavelmente para o delineamento desse processo, considerando a inexistência de trabalhos anteriores que pudessem ser utilizados.

O primeiro artigo, da autoria de Bandeira e Siqueira (1997), lida com o misticismo e a religiosidade que acompanham a história de Brasília, sobre a qual é projetado um caráter

4. Ver adiante 
milenarista e utópico; de acordo com o texto, Brasília seria a capital do Terceiro Milênio.

Nesse artigo, as autoras mencionam o censo espiritual de 1997, realizado pela Secretaria de Turismo, que revelou a existência no Distrito Federal de 1.074 variações de seitas e religiões, incluindo terreiros e centros espíritas. As autoras também mencionam a estimativa de existência de cerca de 350 grupos ou seitas místico-esotéricas e de 269 templos religiosos, 45 centros kadercistas, 42 pentencostais e 10 de inspiração oriental (Bandeira e Siqueira, 1997, p. 228).

O segundo artigo, da autoria de Santos (1997), discute questões referentes ao patrimônio arquitetônico modernista instalado em Brasília e a-sempre mencionada-diversidade cultural amalgamada na/pela cidade, a partir de uma alentada "densidade simbólica" presente na modernidade urbanística e arquitetônica brasiliense (p. 260).

Já o terceiro artigo, elaborado por Madeira (1997), lida com cultura jovem, rock music e festas em Brasília, aludindo às formas de sociabilidade que brotaram no Planalto Central. A influência exercida por esses três artigos refletiu na inclusão de perguntas sobre misticismo, patrimônio cultural e formas de sociabilidade, tendo em vista que esses aspectos se mostravam relevantes e convenientes para a compreensão do desenvolvimento da produção artística em Brasília, principalmente no que tange ao florescimento do rock brasiliense, como fenômeno de repercussão nacional.

Paviani e Gouveia (2003) organizaram e fizeram publicar um volume de artigos dedicado às controvérsias ambientais de Brasília, nos quais se procura corrigir as mencionadas lacunas, notadamente no que se refere a tópicos relevantes para a compreensão da problemática urbana, tais como a discriminação desigual da lógica social do seu espaço urbano, da sua qualidade ambiental, no que refletem a imagem da cidade, suas práticas socioespaciais e de suas representações. ${ }^{5}$

O livro ora em elaboração também procura, a seu modo, iluminar essa especificidade contra-

5. Trata-se, na verdade, da mais recente publicação da extensa lista escrita ou organizada por Aldo Paviani. ditória, apresentando suas manifestações nos habitus artísticos, ${ }^{6}$ emitidos por um grupo de artistas locais, notadamente aqueles que mereceram algum tipo de distinção social em virtude de suas realizações artísticas. Procurou-se, assim, apresentar fatores de caráter não material que são avaliados de forma contraditória, ora realçando a sua influência na formação dos respectivos habitus artísticos, ora relegando a relevância deles à esfera do desconhecido ou do pouco refletido.

A mencionada escassez de estudos acadêmicos vem sendo preenchida, tornando-se particularmente verdadeira apenas quanto ao fazer artístico. Existem muito poucos trabalhos sobre temas artístico-culturais produzidos em e sobre Brasília. Na verdade, o único livro sobre esses temas, quando do início da pesquisa, foi escrito por Duarte (1983). ${ }^{7}$ Conseqüentemente, qualquer estudo neste campo estava marcado pelo seu espírito pioneiro, o que constitui em si mesmo um tema sempre presente quando o objeto de estudo é Brasília.

Entrementes, em 2004, Brasília foi finalmente premiada com a publicação de duas novas obras em que a produção cultural de Brasília é colocada em relevo. A primeira foi Histórias do teatro brasilense, organizada por Villar $\mathrm{e}$ Carvalho, do Departamento de Artes Cênicas, do Instituto de Artes da Universidade de Brasília. Nessa obra, composta por uma miríade de artigos e depoimentos, celebra-se, sobretudo, o esforço paulatino que se empreende para pre-

6. Sumariamente, habitus, segundo Bourdieu (1996), define um sistema de disposições duradouras, absorvidas pelo indíviduo durante seu período de socialização. Acrescentase apenas que se, às vezes, eles de fato funcionam como princípios inconscientes, é de se esperar que alguns dos expoentes entrevistados não os tenham reconhecido ou apontado.

7. Maria Duarte, educadora, chegou a Brasília em 1970. Quanto à influência da imigração na produção cultural de Brasília, acredita que atualmente as pessoas que vêm para a capital trazem uma carga de problemas e não mais as expectativas e a utopia de antigamente. Hoje em dia, eles já sabem que Brasília é uma cidade já formada, cosmopolita: uma cidade que tem a sua cultura. Nos anos 60 e 70, a produção cultural era quase toda oficial, financiada pela Fundação Cultural, de boa qualidade, mas emergia uma produção alternativa, marginal e bastante criativa. Hoje em dia, a produção é realizada com dificuldade, mas os artistas contam com as benesses oficiais. Ela é ao mesmo tempo mais sofisticada e bem comportada e não há mais um objeto claro a ser contestado. 
encher as lacunas na literatura produzida localmente sobre as artes em geral. Menciona-se, por exemplo, a ocorrência de um boom espacial das casas de espetáculo a partir da década de 1990, onde já se apresentam, em média, cerca de dez espetáculos semanais.

A segunda obra é um luminoso volume apologético sobre a cidade como obra de arte, ela mesma coordenada por Hermuche (2003) e composta de imagens fotográficas suntuosas do Plano Piloto da cidade, visto através do ângulo de sua geometria, de sua carta celeste, de sua vegetação selvagem e estranha, da terra vermelha do cerrado, de sua luminosidade transcendente, de sua flora e fauna (inclusive a humana) prodigiosas. Esta obra confirmou de forma insofismável o novo interesse pelo cerrado preconizado na entrevista de Maria Duarte.

Outros trabalhos (Machado e Magalhães, 1985, e Nunes, 2003 e 2004) enfatizam a discriminação social de classe fomentada pela distribuição espacial desigual dos serviços e equipamentos urbanos, causada principalmente pelas distâncias físicas enfrentadas pela maioria de seus habitantes, especialmente por aqueles que habitam nas cidades-satélites. Não obstante, Madeira (2000) uma vez mais chama a atenção para o processo de formação de tribos urbanas pós-modernas e da cultura da festa como traço emergente de uma cultura brasiliense em formação.

\section{O que disseram as excelências de Brasília}

Os fatores que influenciam a formação de excelências em Brasília, na visão de Maria Duarte, são a educação, o acesso à informação, viagens, a estética (noção de beleza), o espaço muito bonito, o excesso de tempo livre e a forma como se aproveita esse tempo.

Considera Brasília uma cidade mística que proporciona uma grande tolerância religiosa aos seus habitantes. Observou que grande parte da inteligência nacional e dos artistas bem conceituados contribuiu de alguma maneira para a construção de Brasília. O contato com as primeiras excelências e a obra deixada por eles podem ter sido estimuladores. Não sabia dizer se Brasília já teria se tornado um celeiro de excelências. Afirmou apenas que o investimento no campo da cultura na época da construção foi grande. Vieram várias excelências de diversas áreas e isto teve uma influência marcante, com um efeito multiplicador. Acredita muito também na contribuição das pessoas que fizeram a Universidade de Brasília: Lucio Costa, Cláudio Santoro, Oscar Niemeyer, Ana Mae Barbosa, Glenio Bianchetti, Athos Bulcão, Darcy Ribeiro, Nelson Pereira dos Santos, Ferreira Gullar foram algumas das excelências que passaram pela cidade. As excelências geradas em Brasília, para Maria Duarte, seriam: Françoise Forton, Denise Bandeira, irmãos Guimarães, Hugo Rodas e Chico Expedito, no campo das artes cênicas, e Ney Matogrosso, no campo musical. No campo educacional, citou a Bolsa Escola, Escola de Música, Escola de Choro Rafael Rabelo, Universidade de Brasília, Escola Parque e alguma coisa do ensino especial.

Um número razoável de teses e dissertações acadêmicas tem sido produzido acerca de Brasília, nela e alhures, algumas das quais foram publicadas em formato de livro: Queiroz (1991), Lopes (1996), Silva (1997), Carpinteiro (1998), Moreira (1998), Barcellos (1999) e Oliveira (2005).

Entre estes trabalhos acadêmicos, é digna de nota a dissertação de mestrado elaborada por Vargas (1989), que traz o único capítulo acerca do campo da produção cultural em Brasília. Significativamente, este capítulo foi intitulado " $\mathrm{O}$ rosto sem face" pelo autor. Cabe aqui o destaque que Vargas atribui à gestão do fotógrafo Luiz Humberto Martins ${ }^{8}$ na direção excecutiva da Fundação Cultural do Distrito Federal (19851986), apresentada como "experiência de demo-

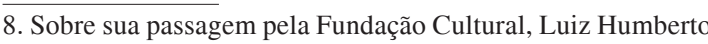
pronunciou: "O meu primeiro projeto foi recuperar e colocar dentro da fundação todas as pessoas que tinham trabalho de resistência durante a ditadura: o Néio Lúcio, com o Projeto Cabeças; Marco Antonio, com o cinema; Fernanda Mee no teatro; Tetê Catalão no jornal. Então eu coloquei meu pessoal e tinha uns projetos rodando lá. Aquilo era uma espécie de albergue dos professores da rede pública que saíam da sala de aula e iam pra lá [...]. Não havia um escalonamento de valor para ocupar o teatro. Nós conseguimos usar o Alberto Nepomuceno que estava encostado, cheio de poeira. No Villa Lobos, conseguimos utilizar o mezanino para as exposições. No foyer, como é uma coisa nobre, nós fizemos sexta-feira a Brasília Popular Orquestra que ia pra lá tocar e a gente dançava, uma coisa sadia[...]".
} 
cratização da política cultural ligada à questão da cidadania" (p. 370), apesar de sua curta duração.

Note-se, também, que o trabalho realizado pelo embaixador Wladimir Murtinho à frente da Secretaria de Educação e Cultura do Distrito Federal também mereceu o destaque de, pelo menos, duas excelências (Hugo Rodas e Luiz Áquila). Inquerido a respeito das razões para esse destaque, proveniente de dois artistas dos quais, sabidamente, foi o mentor, assim se pronunciou o ex-secretário:

Fui Secretário de Educação e Cultura do Distrito Federal entre 1974 e 1979. Fiz coisas importantes aqui [...]. Recuperei o Cine Brasília que era um pulgueiro, literalmente, em um dos mais lindos cinemas do país [...]. Com a finalidade de retomar o festival de cinema. Como havia o cinema, ninguém ousou negar a continuação do festival [...]. Ficou e ainda é um extraordinário instrumento [...]. Isso permitiu a retomada da tradição que havia de cinema no Distrito Federal [...]. Depois disso, outra coisa que houve foi fechar a Sala Martins Pena para poder completar o teatro que ficou parado quinze anos. Reabrimos o Teatro Nacional que estava fechado, não havia sido acabado e reabrimos a Sala Martins Pena e fizemos aquela pequena sala de música que é a Sala Alberto Nepomuceno. Tudo isto deu um grande movimento a Brasília [...]. Nessa época foi possível criar a Orquestra Sinfônica do Teatro Nacional que era uma coisa importante. Mas, veja bem, tudo isto não faz os grandes de que vocês estão falando [...]. Tudo isto faz com que, no fundo, haja a possibilidade de manter uma programação correta na cidade. $\mathrm{O}$ que fizemos também foi apoiar o trabalho dos outros, de terceiros, que foi a consolidação da Escola de Música [...]. Completamos o auditório que era importante porque você tinha uma escola de música que não tinha onde tocar [...]. Foram muitas exposições [...]. O importante foi a criação de Centro de Criatividade. Esse centro permitiu também que houvesse um lugar onde se encontrassem as pessoas [...]. Eu acho que no fundo deu possibilidades ao Áquila de fazer as coisas, de se revelar a si mesmo [...]. Eu acho que está errada a importação da idéia de que isso é um celeiro e daqui saem coisas. Não creio que seja verdade. Há pessoas, os Hugo Rodas da vida, os Áquilas [...]. Mas, veja bem, Hugo Rodas fica; Áquila sai e vai se tornar importante na Escola do Parque Lage.
Alguns preferiram mencionar os horizontes e a luminosidade da cidade ensolarada como grandes estímulos para suas criações artísticas. Para esses artistas, o céu é o oceano de Brasília, e seus dias ensolarados uma graça divina a qual todos deveriam usufruir no sentido de melhorar a qualidade dos seus trabalhos de arte.

Sobre o maior tempo livre presumidamente disponível em Brasília, assim avaliou Cildo Meirelles:

Eu acho que Brasília é uma cidade que te permite ter muito tempo [...]. O Rio eu acho uma cidade dispersiva, uma cidade problemática, então você perde muito tempo, quer dizer, fazendo as coisas mais bizarras você perde tempo, você tem que ir à cidade, tem que ir à praia [...] apesar de eu não ser muito praieiro não [...] e não sei, mas eu acho que a praia amplia ainda mais a dispersão.

Discorrendo sobre a mesma questão, Hugo Rodas assim se expressou:

A mim o que impressionou foi a solidão. $\mathrm{Eu}$ toda a vida vivi urbanamente [...]. Se eu trabalhava em um teatro, eu morava a três quadras [...]. Eu não dirijo. Eu odeio perder tempo. Por exemplo, nesses 26 anos, eu passei três anos em São Paulo [...] mas eu saí porque eu não suportava a maneira de administrar o tempo [...] para ir dar uma aula de uma hora, perdia quase três. Aí Brasília foi muito forte nisso. Eu senti essa falta de necessidade de distração. Porque em uma cidade é impressionante como você se distrai [...]. Mas Brasília me deu [...]. Tudo isso sempre alimentou a minha loucura de uma maneira muito mais sossegada, muito mais centrada. Como que isso começou a me ordenar, sabe? Vontade de viver em um lugar em que eu via o horizonte [...]. E isso me deu uma centrada que evidentemente passou ao trabalho. Passou a concretizar-se de alguma maneira em trabalho. Aí nasceu um respeito enorme por esse espaço, pela cidade e o reconhecimento.

Inquirido sobre o interesse da mídia em divulgar a idéia de Brasília como "usina de talentos", Meirelles respondeu:

Não, eu não acho que seja um esforço da mídia [...]. Uma série de pessoas teve sua vida profundamente marcada pela experiência em 
Brasília, mesmo que não continuasse morando aqui, vivendo por aqui. Eu acho que esse sentimento por Brasília é indelével nas pessoas que tiveram a oportunidade de viver essa experiência aqui.

Ao discorrer sobre a plasticidade arquitetônica que esteticiza o espaço urbano de Brasília, Menezes (2003, p. 55) destaca o Teatro Nacional e afirma sua predileção pelo relevo que encobre a pirâmide, "formado por cubos brancos das mais variadas dimensões que, sob a luz do sol, ganham grandeza transcendental".

Em seguida, Menezes se detém sobre o autor da obra, Athos Bulcão, carioca de 85 anos, tornado cidadão candango, "honra e glória de Brasília”. Athos Bulcão também considera esse alto relevo como um de seus trabalhos de que mais gostou, em entrevista concedida à $U n B$ revista, da qual transcreve-se o seguinte trecho:

Aqui em Brasília tinha uma coisa lindíssima que eu só conhecia em Catulo da Paixão Cearense. "Não há, oh gente, oh não, luar como este do sertão.” O que era lindo é que era escuro, e o céu parecia um manto cintilante. Dito assim, soa uma coisa acadêmica, mas parecia mesmo um manto com uma lantejoula ao lado da outra. Aquilo parecia que ia cair na cabeça da gente de tanta estrela. $(2003 \text {, p. } 56)^{9}$

Por outro lado, o jornalista Frederico Moraes considera que a obra pública do Athos Bulcão artista molda "[...] a sensibilidade artística e cromática do morador de Brasília, educando seu olhar para a arte contemporânea" (Jornal de Brasília, Caderno 2, 2/7/1998), insinuando aqui um elemento formador de um habitus estético.

Luiz Áquila, em seu depoimento, também discorreu sobre a influência da luz na sua pintura, quando perguntado sobre sua paisagem de Brasília:

9. O cantor Ney Matogrosso assim se referiu sobre esse fenômeno: "Agora, o céu de Brasília é particularmente importante... Eu, pelo menos, nunca tido noção de um céu, de uma abóbada celeste. Eu vi algo que ocupava os limites de Brasília. Eu não sei se existe em outros estados. Eu nunca tinha visto. Eu já tinha morado em Salvador, Recife, Mato Grosso, Rio de Janeiro e nunca tinha visto isso. Então, para mim, foi muito impactante aquele contato com aquele infinito".
Olha, Brasília tem essa [...]. Quem vem do Rio, onde você vê tanta montanha, tem uma dificuldade com o cerrado. Quando você começa a entrar no cerrado é uma grande descoberta. Esse cerrado que não pode ser visto de longe. Você tem que penetrar e perceber dentro da escala dele, então aí é uma grande descoberta. As relações de horizonte horizontais e verticais que você tem em Brasília. Você tem a grande horizontal da natureza e a verticalidade da construção, a geometria, a cultura entrando e essa cunha... Brasília é muito bonita, os reflexos da paisagem nos vidros, nos automóveis, quer dizer [...] essa luz estourada. [...]. Olha, no meu período de Brasília, ela se refletia nessa articulação formal: a horizontal e vertical, a relação ente a nuvem e o prédio. Você vê a quina do prédio e a forma sensual e arredondada das nuvens. Essa paisagem sendo recortada pela janela.

Cildo Meireles aduziu a respeito da influência do traçado urbano de Brasília sobre seu trabalho:

Olha só, uma das coisas em que Brasília sempre se fez presente em meu trabalho sempre foi a questão das escalas. Eu acho que Brasília possibilita, sobretudo para quem trabalha nessa área visual, a experiência de uma escala que talvez aqui no Brasil nenhum lugar te dê. Quando se fala no céu de Brasília, no horizonte de Brasília, a gente está falando também de uma coisa a que eu me referi como essa emoção do longe, lejos, essa palavra espanhola que eu acho tão bonita. Uma outra coisa, sem dúvida, é a luz de Brasília, que eu acho que, e não é o meu caso porque embora tenha feito algumas pinturas, eu considero pintura e sobetudo pinturas a óleo uma espécie de religião quer dizer uma coisa muito à parte, muito singular nesse sentido e eu imagino que para o pintor a luz de Brasília propõe uma dimensão muito interessante.

Em relação ao misticismo em Brasília, Cildo Meireles afirmou:

Olha: eu não sou uma pessoa exatamente religiosa [...]. Mas eu acho que Brasília tem alguma coisa estranha em termos de energia. Uma coisa que eu sinto fisicamente e, ainda ontem, eu estava comentando que ia passando na W3, às cinco da tarde, quer dizer um trajeto que eu cansei de fazer e de repente você nota 
que não está transitando assim num território absolutamente intenso de uma força muito misteriosa. Eu acho uma coisa palpável, uma coisa [...]. Eu imagino que é difícil um artista brasiliense não se ligar nesse fato estranho, nessa energia que eu acho que é uma coisa muito presente.

Por outro lado, Siqueira (2003, p. 145 e 146) apresenta a realização da $1^{\text {a }}$ Feira Mística de Brasília, em 1997, como uma manifestação singela do sincretismo e do pluralismo religiosos no Brasil, sob as formas da pluricomposição, da bricolagem e dos trânsitos das suas religiosidades. A pesquisadora observa que "tudo isso indica a construção e a vivência de um novo estilo de vida que implica uma melhor qualidade de vida" (2003, p. 158).

Cabe ainda notar que as experiências e as nuances místicas que abrangem o mito fundador de Brasília nunca são suficientemente exploradas e acentuadas. Nesse sentido, cabe aqui também um registro freudiano de estranheza em relação ao sonho de Dom Bosco, à incorporação de Dulcina de Moraes e à fundação do Vale do Amanhecer pela vidente tia Neiva. Neste artigo, detalha-se brevemente o caso da incorporação de Dulcina de Morais, tendo em vista que está mais diretamente relacionado às circunstâncias de formação do campo artístico brasiliense.

A atriz, professora e diretora de teatro Dulcina de Morais, quando ainda residindo no Rio de Janeiro, depois de haver tentado infrutiferamente a transferência de sua escola e teatro para Brasília, teria recebido "passes" da senhora Aida Ferreira, genitora da atriz Bibi Ferreira, que era mediúnica.

Segundo conta o bailarino e coreógrafo Fernando de Azevedo, que trabalhou com Dulcina (de quem era amigo e confidente) durante decênios, tendo inclusive lecionado balé na Fundação Brasileira de Teatro em Brasília, essa atuação mediúnica realizou-se no momento da escolha do local para a construção do prédio da nova Fundação Brasileira e do Teatro Dulcina em Brasília.

Esse momento histórico do teatro brasileiro, e, sobretudo, para a formação do campo das artes cênicas em Brasília, é assim narrado por Sergio Viotti (1988, p. 40):
O senhor amabilíssimo mostrou-lhe uma área: "Se quer um terreno para localizar a FBT e uma casa de espetáculos, o local é este aqui. No Setor de Diversões Sul. A senhora pode escolher o terreno que quiser". Ela não sabia o que fazer. "Era uma buraqueira vastíssima. Fechei os olhos. Guie o meu dedo, meu Pai, Deus meu, por favor. Era a única coisa que eu conseguia pensar naquele momento. Encolhi as pálpebras. Espetei o indicador. Minha mão avançou. A unha arranhou o fundo de um casulo. Tinha escolhido o meu terreno. Era ali que a Faculdade seria construída. Eu mal podia acreditar. Tínhamos conseguido! Bendita boa educação do Odilon!"

Os três casos mencionados, incluindo a incorporação de Dulcina, são considerados paradigmáticos da mística de Brasília, influenciando e fortalecendo a criação do imaginário sobre a cidade e circunstanciando a formação do seu campo artístico.

De qualquer forma, Dulcina era uma diva, e os depoimentos de Marcelo Saback e Françoise Forton, seus discípulos e que atualmente fazem parte do elenco de atores das telenovelas do Sistema Globo de Televisão, de repercussão mundial, são ilustrativos de sua importância para a formação do campo das artes cênicas em Brasília.

Françoise Forton deixa clara a influência que Dulcina de Morais exerceu na sua vida e em sua formação de atriz:

[...] eu sou da primeira turma da faculdade e meu vestibular foi com a Dulcina. A minha banca examinadora era Dulcina e que foi um desespero. Nossa prova prática foi um monólogo da Joana D'Arc. Fiz, passei e comecei a fazer faculdade e eu tinha aula de interpretação com a Dulcina, o que era uma maravilha, porque Dulcina tinha uma coisa muito forte, evidentemente, que era o talento, a carreira dela etc., mas ela nunca foi uma mulher voltada para o ensino. [...] então você tinha que entender como ela passava essas coisas pra gente. Ela falava muito da disciplina, da formação, do aquecimento, da coisa da diç̧ão que tinha que ser perfeita. A última pessoa lá atrás tinha que ver o suspiro entre um frase e outra. [...] eu acho que sem dúvida ela foi assim um grande presente para Brasília. 
Marcelo Saback assim declarou:

Fui aluno dela [...]. Fazia teatro amador, semiprofissional. Logo no primeiro semestre em educação artística, teve a montagem da Dulcina de Moraes de Bodas de sangue. Eu ia fazer parte do coro de bailarinos e fui escolhido pelo coreógrafo Fernando Azevedo para dizer uma fala. Aí Dulcina, que estava na platéia, subiu no palco e me aplaudiu. E disse: "Você é ator?". "Não, não, sou aluno de educação artística." Ela falou: "Você tem que fazer faculdade de teatro." "Mas eu não fiz vestibular pra teatro." "A faculdade é minha, você faz o que eu quero." E ela era uma personagem... Foi quando se desenvolveu minha paixão pelo teatro. Não pelo que ela me ensinou propriamente, mas pelo que ela foi. A personalidade de Dulcina. Eu entrei na faculdade sem saber quem era Dulcina de Moraes. A ética da profissão eu aprendi em Brasília. Continuo tendo essa ética de Brasília e estranhando a ética que não existe fora de lá. Porque eu aprendi uma ética de escola, uma ética com Dulcina, uma ética com amigos.

Outros artistas preferiram atribuir razões mais objetivas ao aludido diferencial em sua produtividade, tais como a existência das já mencionadas instituições educacionais e de um mercado artístico relativamente grande, constituído por servidores publicos bem pagos do alto escalão do governo nacional estabelecido na cidade e pelas elites locais do comércio, do setor de serviços e das poucas indústrias existentes. Afinal de contas, os mais altos níveis de ganhos, gastos e consumo no país estão localizados em Brasília ou, mais precisamente, no seu Plano Piloto.

O artista plástico Glenio Bianchetti, gaúcho de Bagé, que chegou em Brasília em 1962, assim se pronunciou a respeito dessa questão:

Mas essa coisa de vender... Brasília é uma das cidades que vende mais nacionalmente, sabia disso? Que mais consome arte. Por quê? Não é privilégio de intelectual nem nada disso não. É dinheiro mesmo. Quem tem um nível salarial melhor que os outros estados pode comprar, é lógico. E compra. Aqui, por exemplo, acredito, um quadro caríssimo não vende aqui. Há uma grande fortuna do Rio ou de São Paulo que compra. Mas essa média de arte pequena, de arte menor, aqui em Brasília, tranqüilamente [...].
Eu vendo pra aqui e pra gente de fora. Sempre foi assim. Porque tem muita gente de fora que passa por aqui e chega aqui em casa, me telefona e vem comprar coisa. E aqui em Brasília eu vivo na dependência do meu cargo de aposentado da UnB. Porque, na realidade de Brasília, a única coisa positiva é que tem um nível salarial médio alto e as pessoas compram, consomem. Outra coisa que tá faltando aqui: crítica de arte. Não tem jornais e revistas, não tem crítica especializada.

\section{Conclusões preliminares}

Na verdade, a construção e a permanência do centro brasileiro de decisões políticas em sítio tão longínquo se prestam a todos os tipos de afirmação: seu estilo de vida tedioso; a ausência de praia; sua sociabilidade desnaturada; o excesso de tempo livre desfrutado por um número de habitantes do Plano Piloto; sua dinâmica espacial discriminatória; sua arquitetura padronizada e solene; a desumanização do seu espaço público, criada pelas distâncias físicas estabelecidas entre seus habitantes das cidadessatélites e aqueles do Plano Piloto; o fato de ter sido centro de poderes políticos autoritários; sua referência como sendo uma ilha da fantasia e assim por diante.

Por outro lado, a positividade desse imaginário pode ser encontrada no orgulho de seus pioneiros, expoentes em seus campos específicos; na satisfação que é freqüentemente demonstrada por seus habitantes mais antigos em relação às suas obras, as quais estão quase todas concluídas; no seu reconhecimento pela Unesco como parte do patrimônio cultural da humanidade; a beleza de seus jardins, árvores e áreas verdes, que parecem tornar quase todos cidadãos cordiais e arejados; e, por último, mas com igual importância, na afetividade demonstrada pela cidade por aqueles que nasceram em Brasília, na qual alguns desfrutam de um grau de conforto e qualidade de vida a serem invejados pelos residentes de outros centros metropolitanos do Brasil.

Indubitavelmente, salvo exceções mais materialistas, a aura mística de Brasília é considerada uma importante característica da cultura local, com alguma influência na disposição e na inspiração no sentido da criação artística. Isso 
conduziria a um estilo de vida mais introspectivo e tranqüilo, o que resultaria em uma maior criatividade. Contudo, esta não é considerada uma vantagem muito relevante, mesmo levando em conta que experiências religiosas e alternativas são parte marcante de sua vida quotidiana. Agências que oferecem oportunidades para visitantes usufruírem de excursões em turismo místico estão proliferando. A própria Universidade de Brasília tem oferecido cursos especiais de formação nesse tipo de empreendimento, através do seu Centro de Treinamento em Turismo.

Outros entrevistados enfatizaram o fato de que, na capital nacional, existe mais circulação de informação e conhecimento acerca das artes e dos movimentos artísticos do que em outras localidades do país. Ou, mais precisamente, circulam mais rapidamente do que em outros centros urbanos do Brasil. Nesse sentido, a existência de um grande número de diplomatas estrangeiros, bibliotecas de embaixadas e centros culturais também contribui decisivamente para o estabelecimento de uma produção artística considerável e respeitável na cidade.

Outra questão que vale a pena incluir neste contexto diz respeito à territorialização/desterritorialização da produção artística no mundo contemporâneo. Seria Brasília um sítio territorializado geográfica e artificialmente para dar conta de uma produção desenraizada e orientada para um mercado desterritorializado? Muitos de seus artistas, afinal, depois de formados (primeira geração) não ficaram lá!

A análise das entrevistas demonstra um intricado e sofisticado nível de reflexão a esse respeito. Por exemplo, de início, houve a resistência de três cantoras pops selecionadas entre as excelências, de forma diferenciada, a responder à entrevista, deixando claro que a identificação delas como cantoras brasilienses não procedia e que o hábito da mídia local em localizar o seu território artístico, a partir da origem, da residência ou do início da carreira, representa a utilização de critérios contraproducentes no sentido da projeção de suas carreiras e da aceitação pelos seus públicos consumidores.

Em outras palavras, independentemente de suas considerações a respeito de suas fortes ligações familiares, profissionais e afetivas com a cidade, esse tipo de territorialização cria um tipo de identificação relacionada a uma fase ultrapassada de suas carreiras. Na verdade, as três artistas prefeririam serem nominadas de cantoras pops internacionais. ${ }^{10}$

Por outro lado, houve reações contrárias a esse processo de territorialização e criação de identidade cultural, primeiro por não acreditarem que a grande maioria dos artistas locais de fato nunca pensa que está produzindo arte brasiliense. Ou por acreditarem que a arte, por ser arte, não deve ser regionalizada, o que criaria uma espécie de camisa-de-força para o artista que procura com maior freqüência conceber sua obra como algo a ser projetado nacionalmente e/ou internacionalmente.

\begin{abstract}
This article presents excerpts of a book about the art worlds in Brasília, the modernist capital which was planned as a socialist utopia. The book is in the process of being finalized and is based on the interviews of 23 experts of this field of cultural production. It shows the frontier character of this society and the pioneerism of theses artists, the mystic-esoteric aspects and the ecological influences in their processes of sentimental education. It also presents a critique about the imaginary created about the city as an attempt to create the identity of a cultural site extremely new as based on the cases of artists who reached national and international recognition.
\end{abstract}

Key-words: Brasília; artistc field; modernism; sentimental education.

\section{Referências}

BANDEIRA, L.; SIQUEIRA, D. O profano e o sagrado na construção da Terra Prometida. In: NUNES, B. F. (Org.). Brasília: A construção do cotidiano. Brasília: Paralelo 15, 1997.

BARCELLOS, V. Q. Os parques como espaços públicos de lazer: o caso de Brasília. São Paulo, 1999. Tese (Doutorado) - Faculdade de Arquitetura e Urbanismo da USP.

BOURDIEU, P. As regras da arte. São Paulo: Cia. das Letras, 1996.

CARPINTERO, A. C. C. Brasília: Prática e teoria urbanística no Brasil, 1956-1998. São Paulo, 1998. Tese (Doutorado) - Faculdade de Arquitetura e Urbanismo da USP.

10. Zélia Duncan, Rosa Passos e Cássia Eller (que faleceu antes de ser de fato contactada para a entrevista). 
DUARTE, M. de S. Educação pela arte: o caso Brasília. Brasília: Editora Thesaurus, 1983.

HERMUCHE, W. Abstrata Brasília concreta. São Paulo, 2003.

LOPES, L. C. Brasília, o enigma da esfinge: A construção e os bastidores do poder. Porto Alegre/ São Leopoldo: Editora Unisinos/Editora da UFRGS, 1996.

LUZ, C. Invenção da cidade, 2. ed. São Paulo: Editora Record, 1982.

MACHADO, L. Z.; MAGALHÃES, T. Q. Imagens do espaço, imagens da vida. In: PAVIANI, A. (Org.). Brasília, ideologia em questão - Espaço urbano em questão. São Paulo: Editora Projeto, 1985.

MADEIRA, M. A. Formas de sociabilidade e cultura da festa na juventude Brasiliense nos anos 90. In: NUNES, B. F. (Org.). Brasília: A construção do cotidiano. Brasília, Paralelo 15, 1997.

Música, estilo e cultura urbana. In: TEIXEIRA, J. G. L. C. (Org.). Performance, cultura e espetacularidade. Brasília: Editora da UnB, 2000.

MENEZES, R. A solidão vai acabar com ela. 60 histórias de uma Brasília desconhecida. Rio de Janeiro: Versal Editores, 2003.

MOREIRA, V. M. L. Brasília. A construção da nacionalidade: um meio para muitos fins. Vitória: Editora Edufes, 1998.

NUNES, B. F. A lógica social do espaço de Brasília. In: PAVIANI et GOUVEA(Orgs.). Brasília, controvérsias ambientais. Brasília: Editora da UnB, 2003. (Coleção Brasília).
NUNES, B. F. Brasília, A fantasia corporificada Brasília: Paralelo 15, 2004.

OLIVEIRA, M. S. B. S de. Brasília: o mito na trajetória da nação. Brasília: Paralelo 15, 2005.

PAVIANI, A.; GOUVÊA, L. A. de C. Brasília, controvérsias ambientais. Brasília: Editora da UnB, 2003. (Coleção Brasília).

QUEIROZ, C. Paisagens poderosas e pré-existência. Brasília, 1991. Dissertação (Mestrado) - IAU/UnB.

SANTOS, M. V. M. O patrimonio modernista e a diversidade cultural. In: NUNES, B. F. Brasília: a construção do quotidiano. Brasília: Paralelo 15, 1997.

SILVA, L. S. D. da. A construção de Brasília: modernidade e periferia. Goiânia: Editora UFG, 1997.

SIQUEIRA, D. Novas religiosidades, estilo de vida e sincretismo brasileiro. In: SIQUEIRA, D.; LIMA, $\mathrm{R}$. de L. Sociologia das adesões, novas religiosidades e a busca místico-esotérica na capital do Brasil. Rio de Janeiro: Editora Vieira e Garamond Universitária, 2003.

VARGAS, M. C. Estratificação e mudança social em Brasília. Campinas, 1989. Dissertação (Mestrado) - Universidade Estadual de Campinas.

VILLAR, F. P.; CAVALHO, E. F. (Org.). Histórias do teatro brasiliense. Brasília: Instituto de Artes da UnB, 2004.

VIOTTI, S. Dulcina, primeiros tempos 1908-1937. Rio de Janeiro: MiNC/Fundacen, 1988. 